\title{
Job Satisfaction of Faculty Members in Indian Universities
}

\author{
Minakshi Gautam*, Sukhjeet Kaur and Preeti Sharma \\ Department of Extension Education and Communication management, College of Community \\ Science, Punjab Agricultural University, Ludhiana Punjab, India \\ *Corresponding author
}

\section{Keywords}

Job satisfaction, Faculty members, SAUs, Traditional universities

Article Info

Accepted:

10 March 2020

Available Online:

10 April 2020

\section{A B S T R A C T}

The job satisfaction of employees occupies the important place in the field of human resource management. Faculty of higher education institutes make a big community of this sector. They train, teach and lead their students to work efficiently in the interest of society. Therefore, keeping in view the present scenario of society, educational institutes and the importance of job satisfaction of employees working in the institutions the present study was planned to assess the level of job satisfaction of employees in selected state agricultural universities and traditional universities. Data was collected by using selfstructured questionnaire based on Herzberg's motivation and hygiene theory from 360 faculty members selected by using simple random sampling technique. Job satisfaction was measured on an ordered 5 point likert scale. The data was presented as mean score for each characteristic and employees were categorized into low, medium and high level of job satisfaction. Findings of the study revealed thatall faculty members from selected state agricultural universities (SAUs) were highly satisfied with sense of responsibilities followed by work itself as intrinsic factors and social status followed by job security and salary as extrinsic factors of job satisfaction. Faculty members from traditional universities were highly satisfied with opportunity to achieve and recognition \& rewards as intrinsic factors and highly satisfied with social status of their job from extrinsic factors. Overall analysis of data showed that 56.6 percent faculty members from all SAUs and 42.24 percent of faculty members from all traditional universities had the medium level of job satisfaction. In conclusion, majority of the respondents were found to be moderately satisfied with their jobs and organizations. Therefore, there is a need to make certain improvements so that satisfaction of the employees could be increased which can further lead to more productivity.

\section{Introduction}

Job is not only a main source of income but also an important component of life. Job satisfaction is considered as one of the indicators that show the quality of the professional life of the organization's employees regardless of productivity. It involves all daily events that happen to them will have effects on their overall personal life and their general attitude towards life (Smith and Tugba, 2016). Job satisfaction is defined as a feeling of happiness shown by an employee towards his work (Al Sairafi, 
2008). Wang defines the job satisfaction as the expression by an employee of emotional, corporal and mental feelings towards his work's environment (Wang 2012). Piriyathanalai and Muenjohn defined it as the positive evaluation by the employee of job and his work and which is affected by the work regulations and policies and by his position within the organization (Piriyathanalai and Muenjohn, 2012). While Karmani defines the job satisfaction as being the positive emotive attitudes and states resulting from the overall evaluation made by the employee of their job (Kermani, 2013).

Hajjaj (2015) considered that the job satisfaction represents the reactions resulting from the comparison made by the employee between his expectations and what he gets in the reality from his job. This comparison is the basis of differentiation between many alternatives when choosing a work or an activity which might provide him what he was expecting so that the expected benefits are equal to those he is getting in reality, be it material or moral benefits. Bhatti and Qureshi (2007) noted that job satisfaction leads to productivity through bringing high quality motivation and through enhancing working capabilities of employees.

The job satisfaction (JS) of employees occupies the important place in the field of human resource management. The reason of this importance is twofold. On one side it helps in retaining the employees and on the other side it raises their performance level. According to Hoppock (1935) job satisfaction is "any combination of psychological, physiological, and environmental circumstances that causes a person to say, "I am satisfied with my job".In general, job satisfaction encapsulates an employee's feeling about his/ her job. Research, however, has revealed that job satisfaction is a multidimensional phenomenon, influenced by several internal and external factors, like the individual's values, principles, personality and expectations and the job's nature, the opportunities provided etc. (Davies et al., 2006).On other hand it would raise the satisfaction level of faculty which may be helpful for them to give good performance (Peters and waterman, 1982).

It is not that job satisfaction are beneficial to the individual job holder only, rather it is equally beneficial for the organization concerned. So it becomes important that the employees should be equally committed to the organization so as to give better output. The effectiveness level of an organization necessitates adequate organizational formation, satisfactory sources, consistent policies based on scientific and technological developments and qualified employee with healthy working conditions, and also its aim should be directive for social needs.

It is known that human being is the most important input of any organization. Although the organization has organic, physical and economical conditions for effectiveness, the creative performance of the organization may not be promising unless the human being who is responsible for creativity in an organization has attached importance or the needs and expectations of the person are taken into consideration. Human being is, of course, much more important in the educational organizations than in other organizations (Celep, 2003).

With this study we would throw light on the job satisfaction and also reveal the level of job satisfaction of employees of selected State Agricultural Universities and traditional universities. Therefore, keeping in view the present scenario of society, educational institutes and the importance of job satisfaction of employees in achieving organizations goals, vision and mission, the 
present study entitled "Job Satisfaction of employees in Indian Universities" is planned with the objectives to study the level of job satisfaction of employees in State agriculture universities (SAUs) and traditional universities (T.U) in India.

\section{Materials and Methods}

The present research was conducted in state agricultural universities (SAUs) and traditional universities (T.U) in India. Each SAU and T.U were selected from each zone i.e. East Zone- Assam Agricultural University (AAU), Jorhat and Dibrugarh University (DU), Dibrugarh, Guwahati, Assam, West Zone-Maharana Pratap University of Agriculture and Technology (MPUAT) and Mohan LalSukhadia University (MLSU), Udaipur, Rajasthan, North Zone- Punjab Agricultural University (PAU), Ludhiana and Guru Nanak Dev University (GNDU), Amritsar, Punjab, South Zone- University of Agricultural Sciences (UAS) and Christ University, Bangalore, Karnataka.

Forty five faculty members from each selected universities were selected by using simple random sampling. It included 15 faculty members from each cadre i.e. professors and equivalent, associate professors and equivalent and assistant professors and equivalent were also randomly selected. So total of 360 faculty members were selected from SAUs and traditional universities. Job satisfaction is multidimensional construct made up of intrinsic and extrinsic factors.

These factors were selected on basis of Herzberg's Two factor (Motivator and hygiene) theory. Intrinsic factors (motivator factors) include opportunity of achievement, ability to utilization, recognition and rewards, work itself, sense of responsibilities, advancement and growth and creative work.
Extrinsic factors (hygiene factors) include organizational polices and administration, supervision, working condition, interpersonal relations, job security and salary and social status.

A self-structured questionnaire was developed including number of statements on the basis of characteristics of intrinsic and extrinsic factors. The response of faculty members was recorded on 5-point continuum scale (Likert scale). Mean score was calculated for each characteristics of intrinsic as well as extrinsic factors. Employees were categorized in low, medium and high level of job satisfaction on basis of cumulative mean score.

\section{Results and Discussion}

\section{Job satisfaction of faculty members in state agricultural universities}

Data presented in table 1 revealed the mean score values for of all intrinsic and extrinsic factors were studied for four SAUs i.e. PAU (Punjab), UAS (Karnataka), AAU (Assam) and MPUAT (Rajasthan).

\section{Intrinsic factors}

Since the scores range is 1 to 5 so mean scores values above 3 indicate higher satisfaction while lower than three shows low satisfaction. Data showed that faculty members of PAU were highly satisfied due to fulfilment of motivational factors such as sense of responsibilities (4.33), followed by work itself (4.28), ability to utilization (4.20), opportunity of achievement (4.18), advancement and growth (4.18), recognition and reward (4.13) but least satisfied with opportunity for creative work (3.93).

In UAS, Bangalore faculty members were highly satisfied with both 'Sense of responsibilities' and 'work itself' (4.28) 
followed by ability to utilization (4.19), opportunity of achievement (4.18), advancement and growth (4.12), recognition and reward (4.07) and moderately satisfied with creative work (3.98) opportunity. AAU faculty members were highly satisfied with advancement and growth (4.13) followed by work itself (4.12), opportunity of achievement and sense of responsibilities (4.07), recognition and reward (4.03), ability to utilization (4.01) and moderately satisfied by creative work (3.78) opportunities.

In MPUAT, faculty members were highly satisfied with sense of responsibilities (4.27) followed by work itself (4.26), opportunity of achievement (4.18), advancement and growth (4.15), ability of utilization (4.14), recognition and rewards (4.08) and moderately satisfied with the creative work (3.91). It is observed from data that faculty of SAUs was not as satisfied with creative work as with other dimensions of intrinsic factors. Combined data from SAUs showed that high level of job satisfaction with intrinsic factor such as work itself and sense of responsibilities.

\section{Extrinsic factors}

Analysis of result showed in table 1 revealed that the social status (mean score 4.33) was highly rated extrinsic factor of job satisfaction followed by job security and salary (4.32) and supervision (4.17), work conditions (4.09). Employees were satisfied moderately by interpersonal relations (3.94)and organizational polices and administration (3.92) among the faculty members of PAU.

In UAS, faculty members were highly satisfied with maintaining social status of their jobs (4.34) followed by job security and salary (4.28), supervision (4.16), working condition (4.12), interpersonal relations (4.04) and less satisfied with organizational policies and administrations. Faculty members of
AAU were highly satisfied with the provision of social status of their job (4.34) followed by job security and salary (4.24), working conditions (4.08), interpersonal relations (4.03), supervision (4.00) and moderately satisfied by organizational polices and administration (3.91). In MPUAT, supervision (4.19) made the major extrinsic factor followed by social status (4.08), job security and status (4.03) and moderately satisfied by working conditions (3.99), interpersonal relations (3.94) and organizational policies and administration (3.93).

Analysis of variance value shows that job satisfaction of selected universities was different in extrinsic factors like supervision, job security and salary and social status. This difference was significant at one percent level of significance in case of job security and social status while difference in job satisfaction regarding supervision was significant at five per cent level of significance.

Combined data showed that the faculty of the SAUs were highly satisfied with the extrinsic factors such as job security and salary and social status. Job security and salary is important for faculty motivation and boost the morale and ultimately increase the efficiency of faculty members of university.

Overall it was found that faculty members of PAU and UAS (mean score 4.15) were highly satisfied with their job followed by faculty members of MPUAT (Mean score 4.08) and AAU (mean score 4.07). F value indicated that difference in job satisfaction scores of selected SAUs was significant at five percent level of significance. Bhati (2012) in his research work showed that the performance of employee is affected by different factors like organization policy, nature of supervisor superior to employee. 
Nerison (1999) conducted study on job satisfaction among vocational rehabilitation counsellors in a Midwestern state in USA. The results showed that there was a significant level of satisfaction and intrinsic and extrinsic satisfaction factors were similar to other norms gathered by the University of Minnesota, Vocational Psychological Research. Bhatnagar (2014) conducted a study on 'Determinants of motivation and job satisfaction among primary health workers: case studies from Nigeria and India' and found that health workers perceived to be motivated by both intrinsic (self-efficacy, religion, choice of profession) and extrinsic (good working environment including supportive supervision, monetary incentives, recognition, organizational justice) factors.

Moreover, they considered supervision and leadership from within the faculty provided by the officer in-charge, to be more effective than from the district health management team. But they were dissatisfied with inadequate remuneration and an unequal salary structure. Higher job satisfaction was found to be associated with receiving supervision and permanent employment. It was found that faculty in all selected SAUs were more satisfied with intrinsic factors as compared to extrinsic factors. Intrinsic factors are motivating factors while extrinsic factors lead to motivation at work place or in other words provide motivating environment to employees.

\section{Level of job satisfaction of faculty members of SAUs}

On the basis of mean scores of job satisfaction, faculty members were categorized into low $(<3)$, medium (3-4) and high (>4) level of job satisfaction. Results revealed that same percentage $(08.89 \%)$ of faculty members from UAS and MPUAT had low level of job satisfaction, followed by
06.67 per cent of faculty member from PAU in the same category while no one in AAU came under the low category. In medium category, more than half and same percentage of the selected faculty members $(62.22 \%)$ from both AAU and MPUAT followed by 55.56 percent in PAU and less than half $(46.67 \%)$ of selected faculty members in UAS had the medium level of job satisfaction. In high level of job satisfaction, less than half $(44.44 \%)$ of selected faculty members in UAS, same percentage $(37.78 \%)$ of faculty members both from PAU and AAU and only 28.89 percentage of faculty members from MPUAT came under the high level of job satisfaction.

Overall analysed data exhibited that more than half $(56.66 \%)$ of selected faculty members from all selected SAUs were at medium level of job satisfaction, 37.22 percent were highly satisfied and only 06.11 percent of faculty members come under low level category of job satisfaction. Mohan (2000) in a study on job performance and job satisfaction of Assistant Agricultural Officers also found that majority of Assistant Agricultural Officers $((67.07 \%)$ had medium job satisfaction, whereas, 20.73 percent had low and only 12.19 percent had high job satisfaction. Manjunath (2004) in his study found that majority $(95.24 \%)$ of the extension workers were in medium job satisfaction category, while only 4.76 per cent of them were in high job satisfaction category.

It was observed that none of the extension workers belonged to low job satisfaction category. Gautam et al., (2006) reported that the overall job satisfaction of the faculty members was moderate. The younger faculty members were more satisfied as compared to those with a longer service period. Yadav (2011) studied 'Job satisfaction of Agricultural scientist of selected State agricultural universities of Northern region' 
revealed that all agricultural scientist were highly satisfied with their job in Northern region, only little differences were found among three universities Punjab agricultural university, GovindBallabh Pant University of Agriculture and Technology and Hissar Agricultural University. Almost same level of job satisfaction was observed in all selected SAUs, this may be attributed to similar job responsibilities and almost similar working environment in all SAUs and are single governing body i.e. Indian Council of Agricultural Research (ICAR) (Table 2).

\section{Job satisfaction of faculty members in traditional universities}

Results showed in table 3 depict the mean score of all intrinsic and extrinsic factors studied for four traditional universities i.e. GNDU (Punjab), CHRIST University (Karnataka), DU (Assam) and MLSU (Rajasthan).

\section{Intrinsic factors}

Analysis of results shows that faculty members of GNDU were highly satisfied with recognition and reward (4.16) followed by work itself (4.07), sense of responsibilities (4.04) and moderately satisfied with ability to utilization (3.65), creative work (3.53), advancement and growth (3.37) and less satisfied with opportunity of achievement (3.25). In CHRIST university, all faculty members were moderately satisfied with six intrinsic factors of job satisfaction i.e. opportunity of achievement (3.49) followed by ability to utilization (3.24), sense of responsibilities and advancement and growth has same mean scores (3.21), work itself (3.13), recognition and reward (3.10) and least satisfied with creative work (2.75). Faculty of D.U. Assam, members were also moderately satisfied with opportunity of achievement and sense of responsibilities
(3.18), ability to utilization (3.16), advancement and growth (3.13), recognition and reward (3.08) and dissatisfied with the factors such as work itself (2.99) and creative work (2.57) respectively. In MLSU, faculty members were highly satisfied with the factors of job satisfaction such as sense of responsibilities (3.96) followed by opportunity of achievement (3.70), ability of utilization (3.63), creative work (3.56) opportunities, recognition and rewards (3.51), work itself (3.50) and least satisfied with the factor advancement and growth (3.49).

Analysis of variance value revealed that differences in the job satisfaction scores of the faculty of selected traditional universities on all intrinsic factors were significant at one percent level of significance. Combined data showed that the faculty members of all traditional universities were highly satisfied with the extrinsic factors such as sense of responsibility and recognition and reward.

These both factors sense of responsibility indicated that faculty of the universities were very sensible towards their responsibilities/ work assigned to them and complete their work with in time whereas recognition and rewards is important for their professional growth. Another factor is recognition and reward considered as strategy which includes appreciation, rewards, cherish and build up their confidence and motivate faculty for doing good teaching and research.

\section{Extrinsic factors}

Perusal of data shows that the faculty members from GNDU were highly satisfied with only two extrinsic factors i.e. social status (mean score 4.34) and job security and salary (4.20) and moderately satisfied with rest of the factors i.e. supervision (3.83), organizational polices and administration (3.62), work condition (3.58), and least 
influenced by interpersonal relations (3.51). Faculty in CHRIST university, all the faculty members were moderately satisfied with all the extrinsic factors like supervision (3.14), job security and salary (3.12), maintaining social status of their jobs (3.10), working condition and interpersonal relations have same mean score (2.93) and organizational policies and administrations (2.91). Faculty members of D.U. Assam, were moderately satisfied with only two factors namely job security and salary (3.15) and social status of their job (3.12) and dissatisfied with the factors were supervision (2.96) followed by interpersonal relations (2.93), organizational polices and administration (2.80) and working conditions (2.74) comes at last with which faculty members were moderately dissatisfied.

In MLSU, faculty members were highly satisfied with the supervision (4.09) factor followed by job security and status (3.94), social status (3.88), working condition (3.69), interpersonal relations (3.66) and least influenced by organizational policies and administration (3.64).

$F$ value showed that the difference in factors of job satisfaction of faculty members in all extrinsic factors was significant at one percent level of significance. Combined data revealed that the faculty members of all traditional universities were highly satisfied with the intrinsic factors such as job security and salary and social status of their job.

Social status of job shows that in our society teaching job considered as very reputed job so that individual prefer to this job which have many benefits whereas job security and salary of job indicated that if the salary of the assigned job is high job satisfaction of the faculty were automatically increased because it is the most influential factor of job satisfaction. Similar results were found by
Noordin and Jusoff (2009) that salary to be one of the most important conditions Malaysian academic staff members for their job satisfaction.

Overall analysis of result revealed that faculty members of GNDU (mean score 3.79) were highly satisfied with their jobs followed by faculty of MLSU (Mean score 3.72), CHRIST University (Mean score 3.09) and at DU Assam (3.00) faculty members were neutral (3.00) with their job satisfaction.

Difference in job satisfaction of faculty in these universities was significant at one percent level of significance. Khalid et al., (2012) conducted a study on various facets of job satisfaction among university academicians in Punjab Province, Pakistan.

They observed that a pay difference does exist between private and public universities in Pakistan. Academicians in private sector universities were more satisfied with their pay, supervision, and promotional opportunities on the other hand, academicians in public sector universities were found more satisfied with co-worker's behaviour and job security. Masum et al., (2015) similarly showed that the salary and job security and work conditions stood out as significant contributor for job satisfaction of academics in private universities of Bangladesh.

Results also revealed that faculty of GNDU and MLSU were more satisfied with extrinsic factors than intrinsic factors. While the faculty of CHRIST University and DU Assam were more satisfied with intrinsic factors than extrinsic factors. Intrinsic factors are motivational factors, also known as satisfiers. Faculty high on these factors have superior performance loading to positive satisfaction. Extrinsic factors are essential for motivation at workplace. Absence or non- existence of these factors leads to dissatisfaction. 
Level of job satisfaction of faculty members of traditional universities

On the basis of mean scores of job satisfaction, faculty members were categorized into low $(<3)$, medium(3-4) and high (>4) level of job satisfaction.

On the basis of analysed data it was revealed that, majority $(71.11 \%)$ of faculty members from DU Assam fell under the category of low level of job satisfaction, more than half (53.33\%) of selected faculty from CHRIST university and only 2.22 percentage of faculty from MLSU came under the low level category of job satisfaction.
In medium category, more than half and same percentage $(51.11 \%)$ of the selected faculty members were from GNDU and MLSU followed by 42.22 per cent from CHRIST University only 24.44 percentage of faculty members from DU Assam came under the medium level category of job satisfaction. In high level category of job satisfaction, less than half $(48.89 \%)$ of selected faculty members were from GNDU followed by MLSU (46.67\%) and same percentage (4.44\%) of faculty members from both universities CHRIST University and DU Assam came under high level category of job satisfaction (Table 4).

Table.1 Job satisfaction of faculty members in selected state agricultural universities $(n=180)$

\begin{tabular}{|c|c|c|c|c|c|c|}
\hline \multirow[t]{2}{*}{ S. No. } & \multirow{2}{*}{$\begin{array}{l}\text { Job Satisfaction } \\
\text { Parameters }\end{array}$} & \multicolumn{4}{|c|}{ Mean \pm SD (Score range- $(1-5))$} & \multirow[t]{2}{*}{ Fvalue } \\
\hline & & PAU & UAS & AAU & MPUAT & \\
\hline \multicolumn{7}{|c|}{ INTRINSIC FACTOR } \\
\hline 1 & $\begin{array}{l}\text { Opportunity of } \\
\text { achievement }\end{array}$ & $4.18 \pm 0.46$ & $4.18 \pm 0.48$ & $4.07 \pm 0.40$ & $4.18 \pm 0.45$ & 0.735 \\
\hline 2 & Ability to utilization & $4.20 \pm 0.39$ & $4.19 \pm 0.41$ & $4.01 \pm 0.43$ & $4.14 \pm 0.41$ & 2.031 \\
\hline 3 & Recognition and reward & $4.13 \pm 0.32$ & $4.07 \pm 0.45$ & $4.03 \pm 0.43$ & $4.08 \pm 0.44$ & 0.504 \\
\hline 4 & Work Itself & $4.28 \pm 0.36$ & $4.28 \pm 0.42$ & $4.12 \pm 0.34$ & $4.26 \pm 0.39$ & 1.871 \\
\hline 5 & Sense of responsibilities & $4.33 \pm 0.47$ & $4.28 \pm 0.51$ & $4.07 \pm 0.41$ & $4.27 \pm 0.53$ & 2.409 \\
\hline 6 & Advancement and growth & $4.18 \pm 0.45$ & $4.12 \pm 0.45$ & $4.13 \pm 0.44$ & $4.15 \pm 0.41$ & 0.182 \\
\hline \multirow[t]{2}{*}{7} & Creative work & $3.93 \pm 0.43$ & $3.98 \pm 0.47$ & $3.78 \pm 0.56$ & $3.91 \pm 0.46$ & 1.480 \\
\hline & Overall & $4.18 \pm 0.22$ & $4.16 \pm 0.26$ & $4.03 \pm 0.23$ & $4.14 \pm 0.27$ & 3.319* \\
\hline \multicolumn{7}{|c|}{ EXTRINSIC FACTOR } \\
\hline 1 & $\begin{array}{l}\text { Organization polices } \\
\text { and administration }\end{array}$ & $3.92 \pm 0.34$ & $3.92 \pm 0.34$ & $3.91 \pm 0.33$ & $3.93 \pm 0.35$ & 0.048 \\
\hline 2 & Supervision & $4.17 \pm 0.32$ & $4.16 \pm 0.33$ & $4.00 \pm 0.32$ & $4.19 \pm 0.34$ & 3.073* \\
\hline 3 & Working condition & $4.09 \pm 0.43$ & $4.12 \pm 0.40$ & $4.08 \pm 0.30$ & $3.99 \pm 0.47$ & 0.794 \\
\hline 4 & Interpersonal relations & $3.94 \pm 0.43$ & $4.04 \pm 0.51$ & $4.03 \pm 0.47$ & $3.94 \pm 0.55$ & 0.557 \\
\hline 5 & Job security and salary & $4.32 \pm 0.28$ & $4.28 \pm 0.34$ & $4.24 \pm 0.31$ & $4.03 \pm 0.54$ & $5.305 * *$ \\
\hline 6 & Social status & $4.33 \pm 0.35$ & $4.34 \pm 0.37$ & $4.34 \pm 0.41$ & $4.08 \pm 0.46$ & $4.823 * *$ \\
\hline & Overall & $4.13 \pm 0.16$ & $4.14 \pm 0.19$ & $4.10 \pm 0.15$ & $4.03 \pm 0.25$ & $3.360 *$ \\
\hline & $\begin{array}{l}\text { JOB } \\
\text { ATISFACTION }\end{array}$ & $4.15 \pm 0.16$ & $4.15 \pm 0.20$ & $4.07 \pm 0.13$ & $4.08 \pm 0.22$ & $2.731 *$ \\
\hline
\end{tabular}

** Significant difference at the 0.01 level (2-tailed).

* Significant difference at the 0.05 level (2-tailed). 
Table.2 Distribution of faculty across state agricultural universities according to level of job satisfaction

\begin{tabular}{|c|c|c|c|c|c|}
\hline \multirow{2}{*}{$\begin{array}{c}\text { Level of } \\
\text { Job Satisfaction }\end{array}$} & \multicolumn{5}{|c|}{ SAUs } \\
\cline { 2 - 6 } & PAU & UAS & AAU & MPUAT & OVERALL \\
\cline { 2 - 6 } & $\begin{array}{c}\text { frequency } \\
(\mathbf{\%})\end{array}$ & $\begin{array}{c}\text { frequency } \\
\text { frequency }\end{array}$ & $\begin{array}{c}\text { frequency } \\
\text { frequency }\end{array}$ & $\left(\begin{array}{c}\mathbf{\%}) \\
(\%)\end{array}\right.$ \\
\hline Low & 03 & 4 & 0 & 4 & 11 \\
$(<\mathbf{3})$ & $(6.67 \%)$ & $(8.89 \%)$ & $(0.00 \%)$ & $(8.89 \%)$ & $(6.11 \%)$ \\
\hline Medium & 25 & 21 & 28 & 28 & 102 \\
$(\mathbf{3 - 4 )}$ & $(55.56 \%)$ & $(46.67 \%)$ & $(62.22 \%)$ & $(62.22 \%)$ & $(56.66 \%)$ \\
\hline High & 17 & 20 & 17 & 13 & 67 \\
$(\mathbf{( 4 )}$ & $(37.78 \%)$ & $(44.44 \%)$ & $(37.78 \%)$ & $(28.89 \%)$ & $(37.22 \%)$ \\
\hline
\end{tabular}

Table.3 Job satisfaction of faculty in traditional universities $(n=180)$

\begin{tabular}{|c|c|c|c|c|c|c|}
\hline \multirow{2}{*}{$\begin{array}{l}\text { S. } \\
\text { No }\end{array}$} & \multirow{2}{*}{$\begin{array}{l}\text { Job Satisfaction } \\
\text { Parameters }\end{array}$} & \multicolumn{4}{|c|}{ MEAN \pm SD (Score range- (1-5)) } & \multirow{2}{*}{$\begin{array}{c}F \\
\text { value }\end{array}$} \\
\hline & & GNDU & CHRIST & DU & MLSU & \\
\hline \multicolumn{7}{|c|}{ INTRINSIC FACTOR } \\
\hline 1 & Opportunity of achievement & $3.25 \pm 0.88$ & $3.49 \pm 0.56$ & $3.18 \pm 0.58$ & $3.70 \pm 0.72$ & $5.120 * *$ \\
\hline 2 & Ability to utilization & $3.65 \pm 0.76$ & $3.24 \pm 0.48$ & $3.16 \pm 0.52$ & $3.63 \pm 0.74$ & $7.165 * *$ \\
\hline 3 & Recognition and reward & $4.16 \pm 0.32$ & $3.10 \pm 0.47$ & $3.08 \pm 0.41$ & $3.51 \pm 0.60$ & $53.793 * *$ \\
\hline 4 & Work Itself & $4.07 \pm 0.62$ & $3.13 \pm 0.79$ & $2.99 \pm 0.76$ & $3.50 \pm 0.74$ & $19.646^{* *}$ \\
\hline 5 & Sense of responsibilities & $4.04 \pm 0.68$ & $3.21 \pm 0.68$ & $3.18 \pm 0.68$ & $3.96 \pm 0.78$ & $19.762 * *$ \\
\hline 6 & Advancement and growth & $3.37 \pm 0.92$ & $3.21 \pm 0.65$ & $3.13 \pm 0.68$ & $3.49 \pm 0.83$ & $1.885^{* *}$ \\
\hline \multirow[t]{2}{*}{7} & Creative work & $3.53 \pm 0.83$ & $2.75 \pm 0.62$ & $2.57 \pm 0.61$ & $3.56 \pm 0.77$ & $23.743 * *$ \\
\hline & Overall & $3.72 \pm 0.37$ & $3.16 \pm 0.36$ & $3.04 \pm 0.34$ & $3.62 \pm 0.42$ & 36.103** \\
\hline \multicolumn{7}{|c|}{ EXTRINSIC FACTOR } \\
\hline 1 & $\begin{array}{l}\text { Organization polices and } \\
\text { administration }\end{array}$ & $3.62 \pm 0.57$ & $2.91 \pm 0.50$ & $2.80 \pm 0.47$ & $3.64 \pm 0.59$ & $31.854 * *$ \\
\hline 2 & Supervision & $3.83 \pm 0.55$ & $3.14 \pm 0.56$ & $2.96 \pm 0.57$ & $4.09 \pm 0.47$ & $45.486^{* *}$ \\
\hline 3 & Working condition & $3.58 \pm 0.70$ & $2.93 \pm 0.54$ & $2.74 \pm 0.56$ & $3.69 \pm 0.76$ & $23.907 * *$ \\
\hline 4 & Interpersonal relations & $3.51 \pm 0.81$ & $2.93 \pm 0.76$ & $2.93 \pm 0.73$ & $3.66 \pm 0.66$ & $11.981 * *$ \\
\hline 5 & Job security and salary & $4.20 \pm 0.41$ & $3.12 \pm 0.56$ & $3.15 \pm 0.53$ & $3.94 \pm 0.57$ & $49.860 * *$ \\
\hline \multirow[t]{3}{*}{6} & Social status & $4.34 \pm 0.35$ & $3.10 \pm 0.51$ & $3.12 \pm 0.48$ & $3.88 \pm 0.54$ & $73.820^{* *}$ \\
\hline & Overall & $3.85 \pm 0.29$ & $3.02 \pm 0.34$ & $2.95 \pm 0.33$ & $3.82 \pm 0.39$ & $94.657 * *$ \\
\hline & JOB SATIS FACTION & $3.79 \pm 0.28$ & $3.09 \pm 0.33$ & $3.00 \pm 0.30$ & $3.72 \pm 0.30$ & 83.052** \\
\hline
\end{tabular}

** Significant difference at the 0.01 level (2-tailed).

*Significant difference at the 0.05 level (2-tailed). 
Table.4 Distribution of faculty across traditional universities according to level of job satisfaction $(n=180)$

\begin{tabular}{|c|c|c|c|c|c|}
\hline \multirow{2}{*}{$\begin{array}{c}\text { Level of job } \\
\text { satisfaction }\end{array}$} & \multicolumn{5}{|c|}{ Mean Score range (1-5)) } \\
\cline { 2 - 6 } & GNDU & CHRIST & DU & MLSU & OVERALL \\
\cline { 2 - 6 } & $\begin{array}{c}\text { frequency } \\
(\mathbf{\%})\end{array}$ & $\begin{array}{c}\text { frequency } \\
\text { frequency }\end{array}$ & $\begin{array}{c}\text { frequency } \\
\text { frequ) }\end{array}$ & $\begin{array}{c}\text { Frequency } \\
(\%)\end{array}$ \\
\hline Low & 0 & 24 & 32 & 1 & 57 \\
\hline$(<3)$ & $(0.00 \%)$ & $(53.33 \%)$ & $(71.11 \%)$ & $(2.22 \%)$ & $(31.67 \%)$ \\
\hline Medium & 23 & 19 & 11 & 23 & 76 \\
$(\mathbf{3 - 4 )}$ & $(51.11)$ & $(42.22 \%)$ & $(24.44 \%)$ & $(51.11 \%)$ & $(42.22 \%)$ \\
\hline High & 22 & 2 & 2 & 21 & 47 \\
$(\mathbf{4})$ & $(48.89 \%)$ & $(4.44 \%)$ & $(4.44 \%)$ & $(46.67 \%)$ & $(26.11 \%)$ \\
\hline
\end{tabular}

Overall data showed that less than half $(42.22 \%)$ of faculty members from all selected traditional universities were at the medium level of job satisfaction, 31.67 per cent faculty members had low level of job satisfaction and 26.11 percent faculty members were highly satisfied with their job. Similarly, Manjunath (2004) found that majority $(95.24 \%)$ of the extension scientists of University of Agricultural Sciences, Dharwad Karnataka were in medium job satisfaction category while only 4.76 per cent of them were in high satisfaction category. It was observed that none of extension scientist belonged to low job satisfaction category.Singh and Kaur (2015) conducted a study 'Job satisfaction among agriculture development officers (ADOs) and horticulture development officers (HDOs) of Punjab' concluded that majority of the ADOs and HDOs were having medium to high level of job satisfaction. Similarly, Kaur (2014) in their study in government and private colleges of Ludhiana city, Punjab showed that teachers in both type of colleges were highly satisfied with their job.

In present study on the basis of both factors Intrinsic (Opportunity of achievement, Ability to utilization, Recognition and reward, Work Itself, Sense of responsibilities, Advancement and growth and Creative work) and extrinsic factors (Organization polices and administration, Supervision, Working condition, Interpersonal relations, Job security and salary and Social status) of faculty's job satisfaction among Indian universities are extracted.

These factors influence faculty to take decision that they should stay or leave their job. Job satisfaction factors are analysed using Anova to identify the important factors for faculty's. Similarly, despite many other dissatisfaction factors of different degree, faculty's showed positive response towards their job. This study also concluded that majority of the respondents were found to be moderately satisfied with their jobs in SAUs as well as traditional universities.

From this study we found that job satisfaction there is needed to make certain improvements like flexible working environment, flexible rules and regulations and strategies supported by higher authorities so that employees can also take benefits and increase their creativity supported by management which can further lead to more productivity in the favour universities.

\section{References}

Al, Sirafi, M. (2008). Administrative Behavior: Human Relations. Dar El 
Wafaa For Printing and Publishing, Cairo, Egypt

Bhatnagar, A. (2014 a). Determinants of motivation and job satisfaction among primary health workers: case studies from Nigeria and India. Ph.D. Dissertation Paper 1. Johns Hopkins University, Baltimore, Maryland, USA.

Bhatti, K. (2012). Impact of employee participation on job satisfaction, employee commitment and employee productivity. International Review of Business Research Papers, 3(2), 54 68.

Bhatti, K. and Qureshi, T. (2007). Impact of employee participation on job satisfaction, employee commitment and employee productivity. International Review of Business Research Papers, 3(2), 54 - 68.

Celep, C. (2003). Teachers' organizational commitment in educational organizations. Psychology, 2: 52-67

Hajjaj, M. (2015). Work pressure and its impact on organizational loyalty: An applied study of managers working in the Ministry of Interior in the Gaza Strip. Unpublished MA, Islamic University, Gaza, Palestine.

Herzberg, F. (1959). The motivation to work. New York: Wiley. Higher Education, 45(1), 43-70.

Hoppock, R. (1935), Job satisfaction. Harper and row, New York NY, page 343.

Kaur, J. (2014). Factors affecting job satisfaction of college lecturers in Ludhiana-an empirical study. Int J Res Dev 3(4): 33-37.

Kermani, Z. Z. (2013). A Study if the Linking between Job Satisfaction and Customer Satisfaction: A Case Study of Iran Insurance, Karman, Iran. Journal of Marketing Development and Competitiveness, 7(4), 104-105.

Khalid, S., Irshad, M. Z., and Mahmood, B.
(2012). Job satisfaction among academic staff: a comparative analysis between public and private sector universities of Punjab, Pakistan. International Journal of Business and Management, 7(1), 126-136.

Manjunath L (2004). Analysis of Job Perspective and Scientific Productivity of Scientists in University of Agricultural Sciences. Ph.D Dissertation, Annamalai University, Dharwad, Tamil Nadu, India.

Masum, A.K.M., Azad, M.A.K., and Beh, L.S., (2015). determinants of academics' job satisfaction: empirical evidences from private universities in Bangladesh. PLoS ONE 10 (2): $\mathrm{e} 0117834$.

Mohan, B. (2000). Study on job performance and job satisfaction of assistant agricultural officers in Northern districts of Karnataka. M.Sc. Thesis. University of Agricultural Sciences, Dharwad. Karnataka.

Nerison, H. A. (1999). A descriptive study of Job Satisfaction among vocational rehabilitation counsellors in Midwestern State. M.Sc. Thesis. University of Wisconsin-Stout, Menomonie Wisconsin, United States.

Noordin, F. and Jusoff, K. (2009). levels of job satisfaction amongst Malaysian Academic staff. Asian SOC. SCI., 5: 122-135.

Peters, T. and Waterman, R. (1982). In Search of Excellence: Lessons from America's Best-Run Companies. New York: Harper and Row Publishers.

Piriyathanalai, W., and Muenjohn, N. (2012). Is There a Like? Employee Satisfaction and Service Quality. World Journal of Management, 4, 8292.

Semih, T., and Tugba, Z. (2016). Social Interactions in Job satisfaction. International Journal of Manpower, 
37(3), 426-455. https://doi.org/10.1108/IJM-04-20140095

Singh, V. and Kaur, P. (2015) Job satisfaction among agriculture development officers and horticulture development officers of Punjab. Int J Res SciInnov 2(9):84-87.

Wang, G. (2012). The Influence of Internal Service Quality on Employee Job Satisfaction at Taiwan Listed
International Tourist Hotels: Using Organizational Culture as the Moderator. World Transactions on Engineering and Technology Education, 10(3), 174-183.

Yadav, K. (2011) Job satisfaction of agricultural scientists of selected State Agricultural Universities of northern region. Ph.D. Dissertation, Punjab Agricultural University, Ludhiana, Punjab, India.

\section{How to cite this article:}

Minakshi Gautam, Sukhjeet Kaur and Preeti Sharma. 2020. Job Satisfaction of Faculty Members in Indian Universities. Int.J.Curr.Microbiol.App.Sci. 9(04): 855-866.

doi: https://doi.org/10.20546/ijcmas.2020.904.103 